\title{
Design \& simulation of dual-band rectifier for ambient RF energy harvesting
}

\author{
Anand Trikolikar ${ }^{1,2 *}$ and Swapnil Lahudkar ${ }^{2}$ \\ Department of Electronics and Telecommunication, AISSMS Institute of Information Technology, Pune, India ${ }^{1}$ \\ Department of Electronics and Telecommunication, JSPM's Imperial College of Engineering \& Research, Wagholi, \\ Pune, India ${ }^{2}$
}

Received: 21-July-2021; Revised: 25-October-2021; Accepted: 29-October-2021

(C)2021 Anand Trikolikar and Swapnil Lahudkar. This is an open access article distributed under the Creative Commons Attribution (CC BY) License, which permits unrestricted use, distribution, and reproduction in any medium, provided the original work is properly cited.

\begin{abstract}
Rectifiers are used for converting Alternating Current $(A C)$ signals received by the antenna into Direct Current (DC) output in Radio Frequency Energy Harvesting (RFEH) System. Different topologies like a half wave, full wave \& bridge wave are used to design rectifies for RFEH system. The purpose of this paper is, to design \& simulate two single frequency $(2.35 \mathrm{GHz}$ and $2.42 \mathrm{GHz})$ and two dual-band $(1.84 \mathrm{GHz} \& 2.42 \mathrm{GHz}$ and $883 \mathrm{MHz} \& 2.35 \mathrm{GHz})$ rectifiers. Initially, rectifier with a matching circuit is designed for a single frequency, after that, a dual-band rectifier with a matching network for all targeted frequencies is designed using transmission lines. A Radio Frequency (RF) to DC conversion efficiency of $45.26 \%$ and output voltage of $1.16 \mathrm{~V}$ is obtained at $2.35 \mathrm{GHz}$, whereas $42.96 \%$ efficiency \& output of $1.13 \mathrm{~V}$ is obtained at $2.42 \mathrm{GHz}$ single frequency rectifier. For dual-band $(1.84 \mathrm{GHz} \& 2.42 \mathrm{GHz})$ rectifier the overall efficiency is $79.46 \%$ at $-4 \mathrm{dBm}$ input power and it increased up to $86.32 \%$ for dual-band $(883 \mathrm{MHz} \& 2.35 \mathrm{GHz})$ rectifier. Finally, a comparison of simulated results of the proposed rectifier with related work is presented.
\end{abstract}

\section{Keywords}

RF energy harvesting, Rectenna, Dual band rectifier, RF to DC conversion efficiency.

\section{Introduction}

Conventional energy sources have limitations like they are non-renewable, produce pollution and limited availability after some years. Due to this reason, researchers are in search of renewable energy sources, which are easily available, non-polluting \& having low cost. Today India is a hub of mobile phones, cell towers, and Radio Frequency (RF) energy is continuously spreading from them, in Radio Frequency Energy Harvesting (RFEH) system this otherwise wasted RF energy from cell towers and Wireless Fidelity (Wi-Fi) hotspots is gathered and converted into DC output [1,2].

Rectenna system consists of an antenna that receives RF signals, a matching network for tuning the impedance of the antenna and rectifier, an Alternating Current (AC) to Direct Current (DC) converter, a DC pass filter to avoid higher order harmonics, and a load that measures the final output of the rectenna.

*Author for correspondence

1383
The antennas used in rectenna are high gain, multiband, omnidirectional, and circularly polarized, whereas in IMN, fewer components are preferred to avoid losses. Techniques such as the use of a resistance compression network in the rectifier and the selection of an optimized value of load resistance are used to design an efficient rectifier [3]. The number of devices in various low power applications is growing by the day, and powering these devices with otherwise wasted RF energy is a better option. A RFEH system can be used as an alternative for the batteries used in low power devices like sensors in Internet of Things (IoT) \& Wireless Sensor Network (WSN) and act as a source of green energy and also reduces microwave pollution generated due to highfrequency waves. A compact and dual band optimized rectenna is required to meet the demand for battery-free operation of low power devices.

The purpose of this paper is to investigate the process of rectifier design using Advanced Design System (ADS) software, as well as to design single frequency and dual band rectifiers for improved Power Conversion Efficiency (PCE). The critical aspect is the improvement in PCE and the proposed rectifier is 
designed for improved value of same. To optimize PCE of rectifier, the value of length $\&$ width of transmission lines used in matching network as well as the value of load resistance is considered. In this paper, two dual-band rectifiers are designed \& simulated and obtained results are compared with related work. This research provides insight into the design and simulation of rectifiers using a simple and effective approach. It also discusses the parameters that influence rectifier efficiency and how to tune those parameters for improved efficiency.

\section{Literature review}

Various rectifier designs, such as single frequency [4-9], dual-band [10-18], tri-band [19-25], quadband [26-28], and broadband [29], are used to create an efficient rectifier.

Muhammed et al. [4] proposed a transmission linebased rectifier operating at $0.9 \mathrm{GHz}$ with an HSMS2850 diode and obtained a conversion efficiency of $50.2 \%$ at $2 \mathrm{dBm}$ input power.

Xiao et al. [5] and Kasar et al. [6] proposed high efficiency $(>70 \%)$ single frequency rectifiers, but they operate at higher input power $(>7 \mathrm{dBm})$.

Ismail and Abd [7] used a reversed L type matching impedance technique to increase PCE and achieved $42 \%$ efficiency at $-10 \mathrm{dBm}$ input power.

Pinto et al. [8] reported a $2.45 \mathrm{GHz}$ rectifier with a 7 stage Villard voltage doubler and a boost circuit that produced an output voltage of $3.3 \mathrm{~V}$, while the output voltage before the boost circuit was $0.204 \mathrm{~V}$.

Narayanan and Thangavel [9] propose a rectenna that operates at $2.45 \mathrm{GHz}$, with a rectifier made using a Cockcroft-Walton voltage doubler and a conversion efficiency of $45 \%$ at $10 \mathrm{dBm}$ input power is obtained.

$\mathrm{Vu}$ Ngoc et al. [10] reported a dual-band (925 \& $2450 \mathrm{MHz}$ ) rectifier with an efficiency of $60 \%$ at 0 $\mathrm{dBm}$, and they proposed a figure of merit equation to evaluate rectifier performance.

Chandravanshi and Akhtar [11] and Rotenberg et al. [12] developed dual band rectifiers with higher efficiency $(>70 \%)$, despite requiring more input power $(>9 \mathrm{dBm})$ to achieve higher performance.

Aboualalaa et al. [13] improves PCE with a foursection matching network and achieves 69\% efficiency at $15.5 \mathrm{dBm}$ input power.
Papadopoulou et al. [14] of presented a rectifier for low-power applications that operates at $2.67 \mathrm{GHz}$ and $3.59 \mathrm{GHz}$. The rectifier is built on a FR-4 substrate and employs a Greinacher voltage doubler topology.

A theoretical analysis of dual band (900 and 1800 $\mathrm{MHz}$ ) rectifier is demonstrated in [15], the author reported PCE of $12.93 \%$ and $8 \%$ at $-30 \mathrm{dBm}$ input power.

Coskuner et al. [16] proposed a rectifier using a metamaterial-based Impedance Matching Network (IMN) that operates at $2.4 \mathrm{GHz}$ and $5 \mathrm{GHz}$, with efficiency of $22 \%$ and $12 \%$ at respective frequencies for input power of $-30 \mathrm{dBm}$. The author concludes that metamaterial transmission lines introduce additional degrees of freedom in design, allowing for impedance matching across multiple bands.

Yusoff et al. [17] reported an ADS simulation of a rectifier for the GSM 900 and $1800 \mathrm{MHz}$ bands. The author reported PCE of $43.51 \%$ and $25.98 \%$ for the $950 \mathrm{MHz}$ and $1850 \mathrm{MHz}$ bands respectively.

Li et al. [18] utilize stepped impedance stub matching circuit to improve circuit efficiency in rectifiers operating at $915 \mathrm{MHz}$ and $2.45 \mathrm{GHz}$. The author concludes that the proposed rectifier has the advantages of a high frequency ratio, a simple configuration, and compact size.

The above-mentioned rectifiers have higher efficiency at the expense of higher input power, and fabrication of those rectifiers is difficult due to their complexity in structure. Because the rectifier is such an important component of the rectenna system, it is critical to design a high efficiency and low-profile rectifier. Single frequency rectifiers have a high efficiency but a low output voltage, whereas multiband and broadband rectifiers have a high output voltage but a low efficiency. As a result, it is preferable to design a dual-band rectifier capable of harvesting energy from various bands while providing ample output voltage and efficiency. Based on the available literature on rectifiers, it is revealed that designing a rectifier with a higher efficiency is difficult. This paper presents the design of simple structured single frequency and dual band rectifiers for Long Term Evaluation (LTE) and Industrial, Scientific, and Medical (ISM) band applications. The dimensions of the proposed rectifier are optimized in simulation through an iterative process. The rectifier is composed on a Flame Retardant 4 (FR-4) substrate with a permittivity of 
4.4, and ADS software [30] is used to simulate its performance.

\section{Methods}

The design of an efficient rectifier is critical in the RFEH system. To design an efficient rectifier, the approach depicted in Figure 1 is used. As illustrated in Figure 1, the initial topology and diode for the rectifier are selected to meet the requirements of higher PCE, and the rectifier's input impedance is calculated to match the standard value of $50 \Omega$. To achieve a higher PCE value, an IMN is used to match the impedance between the antenna and the rectifier, and its components are tuned and optimized.

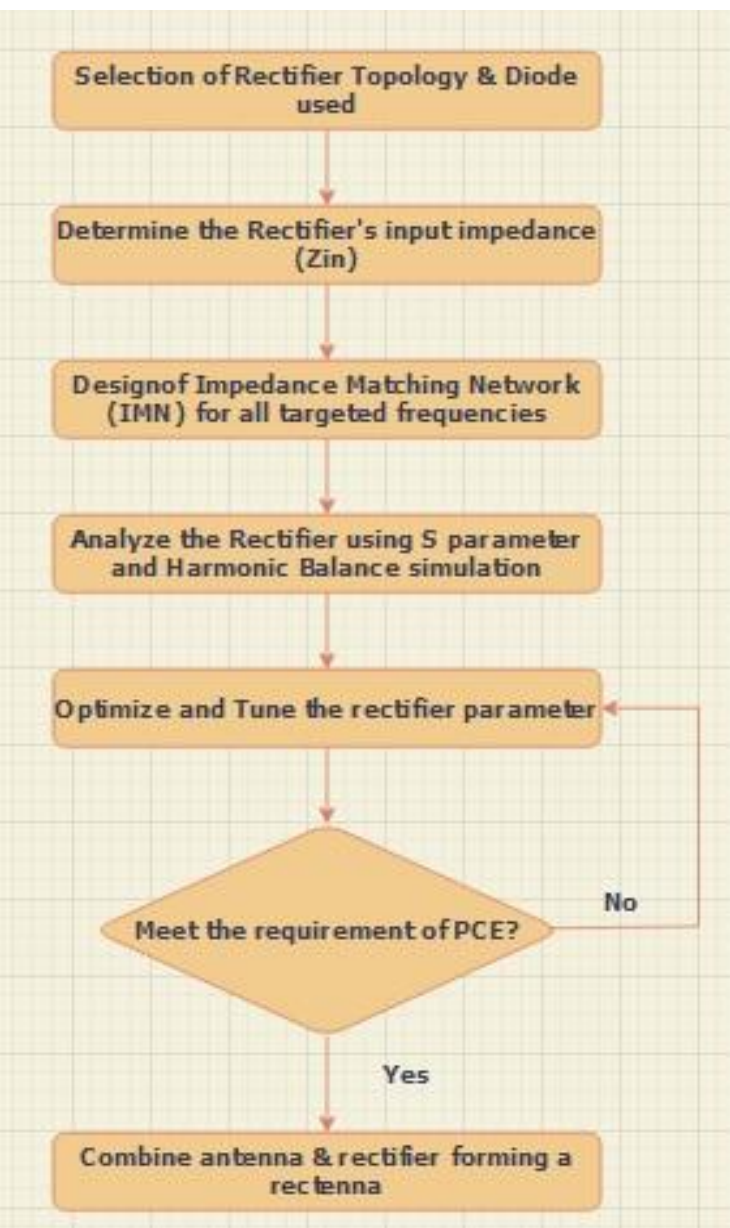

Figure 1 Block diagram of rectifier design approach

The approach used to design the matching network in this paper is simple and provides perfect impedance matching between the antenna and the rectifier, resulting in higher conversion efficiency and output voltage, as described in the results section. This method also employs various optimization algorithms, such as random and gradient, to tune the length of transmission lines used in the circuit in order to achieve the desired resonance frequency. To meet the efficiency requirement, fewer transmission lines and lumped components are used in the design.

To summarize, the following steps are required to design an efficient rectifier:

Step 1: Select the appropriate rectifier topology \& diode to meet the higher PCE requirements.

Step 2: Determine the rectifier's input impedance (Zin).

Step 3: Design of IMN for all targeted frequencies.

Step 4: Analyze the rectifier for the desired frequencies using the $\mathrm{S}$ parameter and harmonic balance Simulation. Step 5: Optimize and tune the rectifier in terms of size, efficiency, and input impedance.

Step 6: Combine antenna \& rectifier forming a rectenna.

\subsection{Design \& optimization of single frequency rectifier}

The PCE of a rectifier is critical aspect to the proposed design; rectifier PCE is primarily determined by the diode, rectifier topology, and load resistance value. This section describes the design of two different rectifiers operating at 2.35 and 2.42 $\mathrm{GHz}$, respectively, using the approach as described above.

3.1.1Selection of rectifier topology \& diode There are many rectifier topologies presented in the RF harvesting research field. The difference between them depends on the position and number of used diodes. Since it provides more output voltage, the proposed rectifier employs a voltage doubler topology. Some locally available diodes are compared with their parameters to select an appropriate diode for rectifier, as shown in Table 1. According to Table 1, HSMS2850 and SMS7630 have a low threshold voltage $(\mathrm{Vt})$, indicating that they require a low amount of input power to turn on, but SMS7630 has a lower breakdown voltage (Vb) and junction capacitance (Jc) than the HSMS2850 diode, so an SMS7630 diode is chosen for rectifier design.

Table 1 Comparison of schottky diodes

\begin{tabular}{lrlll}
\hline Diode & Vt $(\mathbf{V})$ & $\mathbf{V b}(\mathbf{V})$ & $\mathbf{R s}(\boldsymbol{\Omega})$ & $\mathbf{J c}(\mathbf{p F})$ \\
\hline HSMS2860 & 0.65 & 7 & 6 & 0.18 \\
HSMS2850 & 0.35 & 3.8 & 25 & 0.18 \\
SMS7630 & 0.34 & 2 & 20 & 0.14 \\
HSMS2850 & 0.56 & 9 & 5 & 0.7 \\
\hline
\end{tabular}




\subsubsection{Determination of input impedance of voltage} multiplier

The schematic for determining input impedance is shown in Figure 2. It includes a voltage multiplier with an SMS7630 diode and two capacitors (C3 \& C4) with values of $100 \mathrm{pF}$ each. Capacitor $\mathrm{C} 4$ is used for DC blocking before the diode, C3 is used as a DC passing capacitor after the diode, and a load resistance of $4 \mathrm{~K} \Omega$ is used at the output side, with the value optimized for maximum conversion efficiency.

A tone signal with frequencies of $0.9 \mathrm{GHz}, 1.8 \mathrm{GHz}$, and $2.45 \mathrm{GHz}$ is fed into the circuit, and the output voltage (Vout) is measured across the load.
Figure 3 depicts the input impedance values at various frequencies. As illustrated below, the value of input impedance at $880 \mathrm{MHz}$ frequency is 158.815 $\mathrm{j} \times 602.427 \Omega$ (marker $\mathrm{m} 1)$, at $1.84 \mathrm{GHz}$ it is 45.631 $\mathrm{j} \times 301.539 \Omega$ (marker $\mathrm{m} 2)$, at $2.35 \mathrm{GHz}$ it is 31.961 $\times 237.368 \Omega$ (marker $\mathrm{m} 3$ ) and $30.719-* \times 230.614$ at $2.42 \mathrm{GHz}$ respectively. These impedance values must be matched with $50 \Omega$ standard value, which can be accomplished using smith chart utility tool of ADS. Both lumped and distributed components can be used for impedance matching, but at high frequencies, but distributed components are preferred over lumped because they have higher losses.
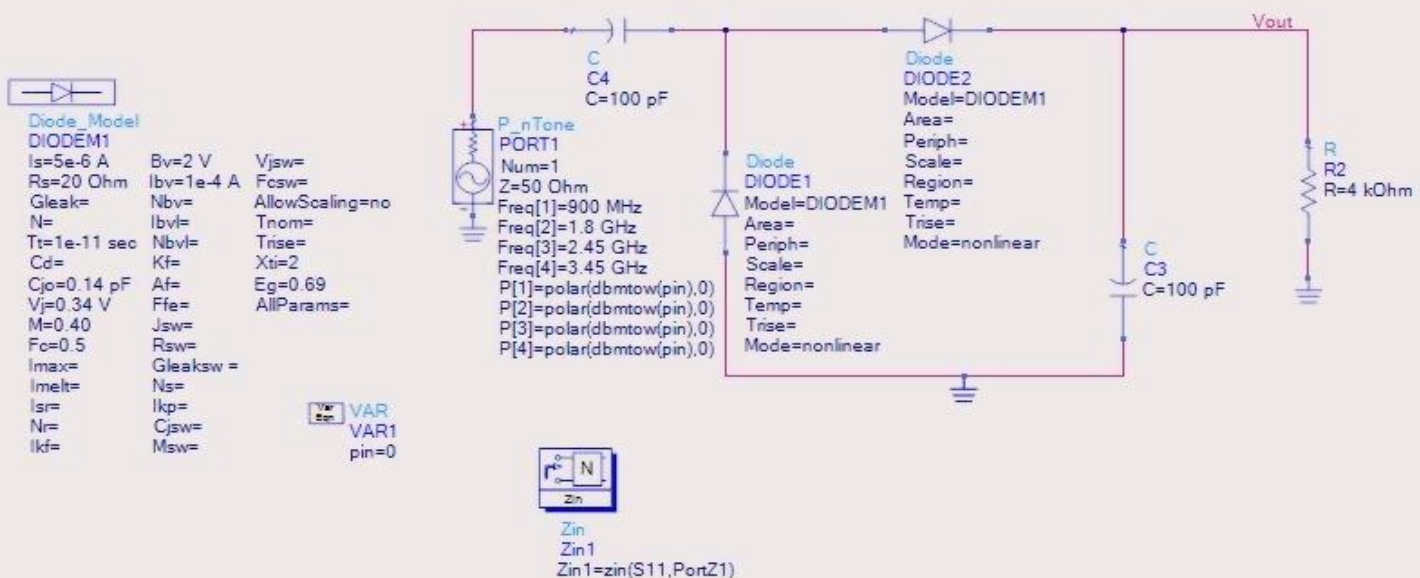

Figure 2 Schematic for finding input impedance of rectifier

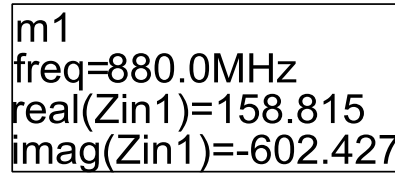

$\mathrm{m} 2$

freq $=1.840 \mathrm{GHz}$

real $(Z$ in 1$)=45.631$

imag $(Z$ in 1$)=-301.539$

$\mathrm{m} 3$

freq $=2.350 \mathrm{GHz}$

real $($ Zin 1$)=31.961$

$\operatorname{imag}(Z i n 1)=-237.368$

$\mathrm{m} 4$

freq $=2.420 \mathrm{GHz}$

real $($ Zin 1$)=30.719$

imag $(Z i n 1)=-230.614$

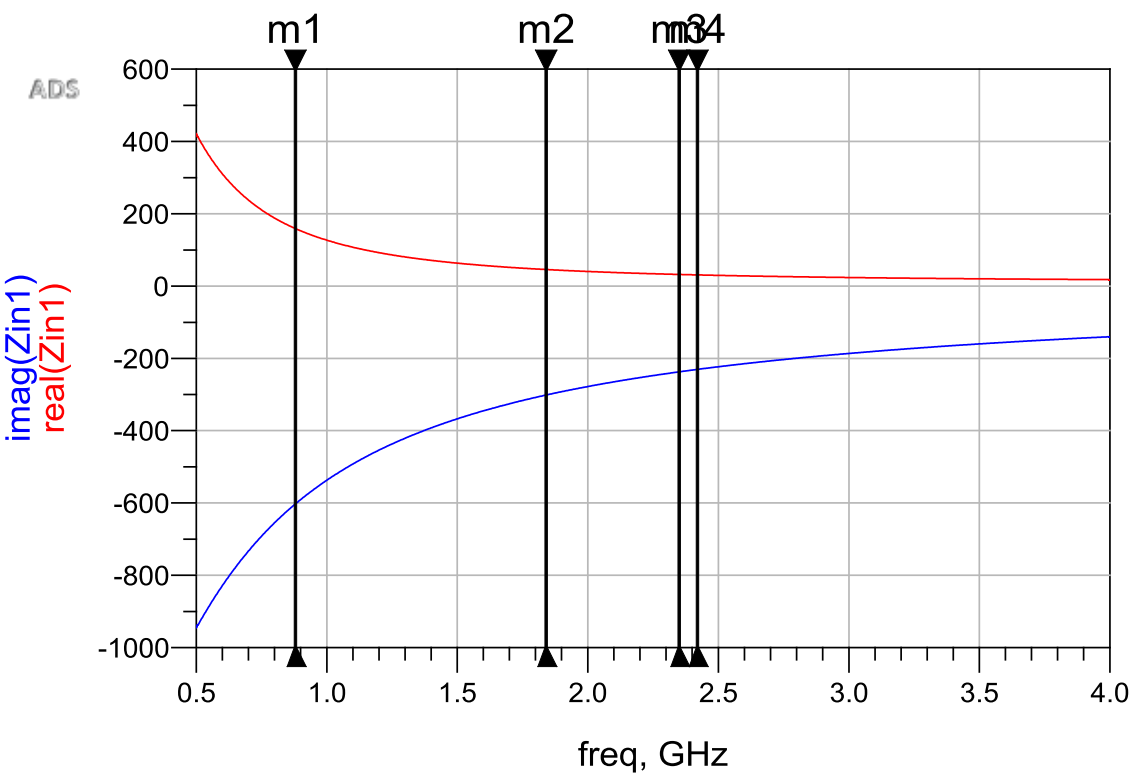

Figure 3 Variation of input impedance at different frequencies 
3.1.3 $\mathrm{S}$ parameter \& harmonics balance simulation at targeted frequency

Figure 4 shows a schematic for simulating a rectifier at a frequency of $2350 \mathrm{MHz}$, which consists of two parts: an IMN and a voltage doubler. At targeted frequencies, a transmission line-based IMN using TL1 and TL2 is designed to match the impedance of a voltage multiplier to $50 \Omega$. The voltage doubler consists of two SMS7630 diodes, capacitors C1 and C2, and stubs TL3, TL4, and TL5.The entire network has been tuned and optimized to match the rectifier at the desired frequency, and the load resistance value has been tuned and optimized for maximum efficiency.

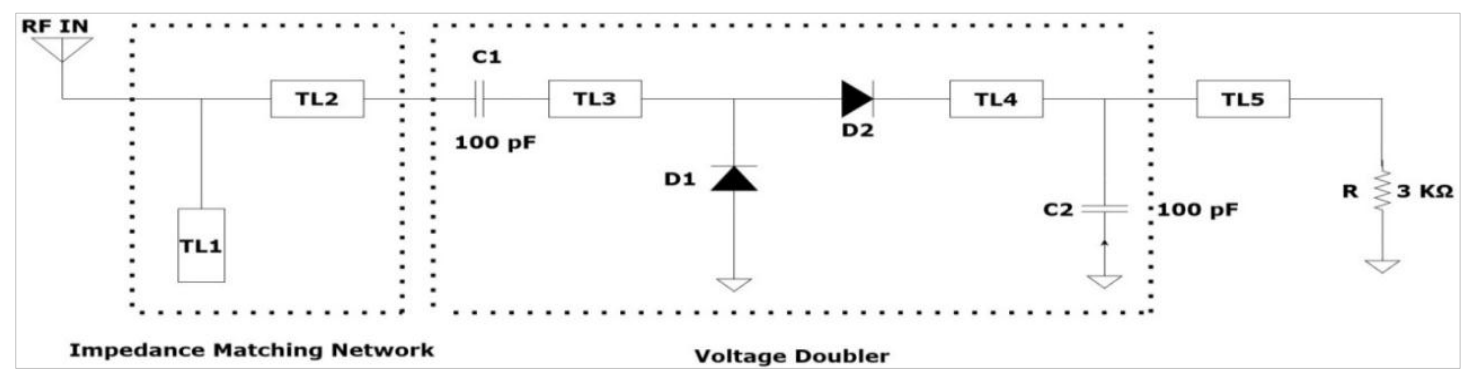

Figure 4 Schematic for rectifier simulation at $2350 \mathrm{MHz}$

The substrate used in simulation is FR4 $\left(\varepsilon_{\mathrm{r}}=4.4\right.$, $\tan \delta$ $=0.02 \& \mathrm{t}=1.6 \mathrm{~mm})$, and an optimized load resistance of $3 \mathrm{~K} \Omega$ is used at output side. A S parameter and harmonic balance simulation is performed on the above circuit, and the width (W) and length (L) of stubs TL1, TL2, TL3, TL4, and TL5 are tuned and optimized for resonance at 2350 $\mathrm{MHz}$ frequency. A rectifier operating at $2420 \mathrm{GHz}$ is also designed by tuning the length and width of transmission lines, and the dimensions of both rectifiers is as shown in Table 2. For ease of design, the width of all transmission lines is set to $3 \mathrm{~mm}$, while the length varies according to the resonance frequency. Table 2 shows that the lengths of TL1, TL2, and TL5 are reduced while the length of TL4 is increased to achieve resonance at $2.42 \mathrm{GHz}$.

Table 2 Dimensions of single frequency rectifier

\begin{tabular}{|c|c|c|c|c|c|}
\hline $\begin{array}{l}\text { Operating } \\
\text { Frequency } \\
\text { (GHz) }\end{array}$ & $\begin{array}{l}\text { W/L } \\
\text { of } \\
\text { TL1 } \\
(\mathbf{m m})\end{array}$ & $\begin{array}{l}\text { W/L } \\
\text { of } \\
\text { TL2 } \\
(\mathbf{m m})\end{array}$ & $\begin{array}{l}\text { W/L } \\
\text { of } \\
\text { TL3 } \\
(\mathbf{m m})\end{array}$ & $\begin{array}{l}\text { W/L } \\
\text { of } \\
\text { TL4 } \\
(\mathbf{m m})\end{array}$ & $\begin{array}{l}\text { W/L } \\
\text { of } \\
\text { TL5 } \\
(\mathbf{m m})\end{array}$ \\
\hline 2.35 & $3 / 14.4$ & $3 / 7.3$ & $3 / 10$ & $3 / 12.5$ & $3 / 15$ \\
\hline 2.42 & $3 / 14.2$ & $3 / 6.6$ & $3 / 10$ & $3 / 13$ & $3 / 12$ \\
\hline
\end{tabular}

3.2Design \& optimization of dual-band rectifier The same approach as described in Figure 1 and the circuit shown in Figure 4 are used to design a dual band $(1.84 \mathrm{GHz} \& 2.42 \mathrm{GHz})$ rectifier. To obtain resonance at two different frequencies, the length and width of transmission lines (TL1 to TL5) used in the circuit are tuned. Table 3 displays the final width and length values for the various stubs used. It is observed that the width of stubs used in IMN (TL1 and TL2) is varied to $1.5 \mathrm{~mm}$ and $14.2 \mathrm{~mm}$ respectively, whereas the width of TL3, TL4, and TL5 remains constant as $3 \mathrm{~mm}$.

Table 3 Optimized parameters of transmission lines used in dual band rectifier

\begin{tabular}{lllll}
\hline $\begin{array}{l}\text { W/L } \\
\text { of TL1 } \\
(\mathbf{m m})\end{array}$ & $\begin{array}{l}\text { W/L } \\
\text { of TL2 } \\
(\mathbf{m m})\end{array}$ & $\begin{array}{l}\text { W/L } \\
\text { of TL3 } \\
(\mathbf{m m})\end{array}$ & $\begin{array}{l}\text { W/L } \\
\text { of TL4 } \\
(\mathbf{m m})\end{array}$ & $\begin{array}{l}\text { W/L } \\
\text { of TL5 } \\
(\mathbf{m m})\end{array}$ \\
\hline $1.5 / 20$ & $14 / 13.8$ & $3 / 18$ & $3 / 14.7$ & $3 / 18$ \\
\hline
\end{tabular}

Figure 5 shows a schematic for designing a dual band rectifier using an SMS7630 diode that operates at 883 $\mathrm{MHz}$ (LTE 5) and $2.35 \mathrm{GHz}$ (LTE 40) bands. In comparison to the previous case, the IMN has been modified by adding two additional stubs TL3 and TL4, and the value of load resistance has been changed to $5 \mathrm{~K} \Omega$, as shown in Figure 5.

Table 4 shows the length and width values of stubs used in the rectifier design that have been tuned and optimized using ADS' tuning and optimization facility. The total size of the second rectifier is increased due to the introduction of additional stubs, but this is required to achieve resonance at LTE frequencies. The size of the rectifier can be reduced even further by modifying the transmission lines in the $\mathrm{L}$ and inverted $\mathrm{U}$ sections. 


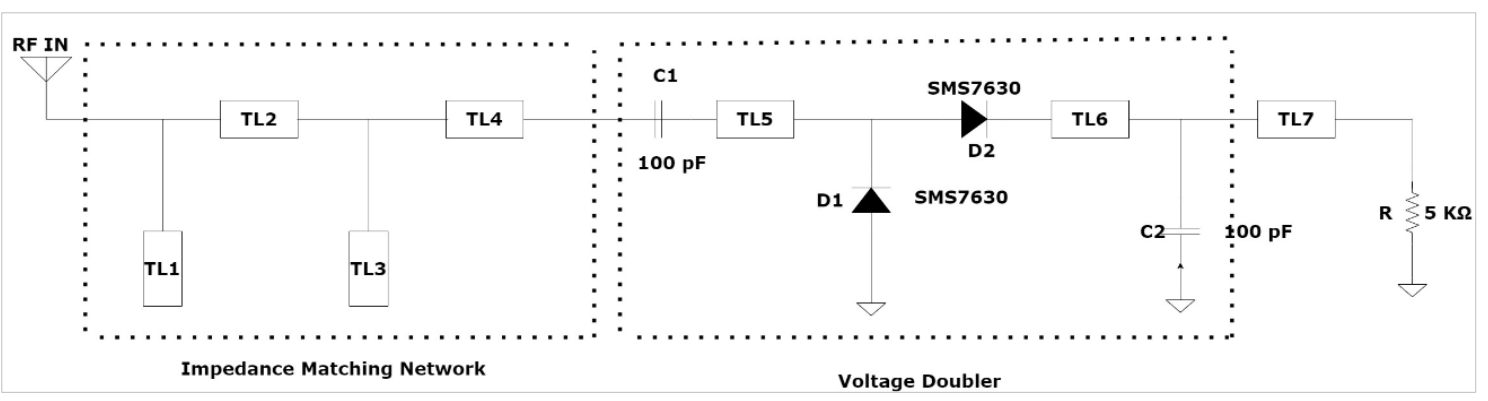

Figure 5 Schematic for dual band rectifier operating at LTE bands

Table 4 Optimized parameters of rectifier at LTE frequency bands

\begin{tabular}{lllllll}
\hline $\begin{array}{l}\text { W/L } \\
\text { of TL1 }(\mathbf{m m})\end{array}$ & $\begin{array}{l}\text { W/L } \\
\text { of TL2 }(\mathbf{m m})\end{array}$ & $\begin{array}{l}\text { W/L } \\
\text { of TL3 }(\mathbf{m m})\end{array}$ & $\begin{array}{l}\text { W/L } \\
\text { of TL4 }(\mathbf{m m})\end{array}$ & $\begin{array}{l}\text { W/L } \\
\text { of TL5 }(\mathbf{m m})\end{array}$ & $\begin{array}{l}\text { W/L } \\
\text { of TL6 }(\mathbf{m m})\end{array}$ & $\begin{array}{l}\text { W/L } \\
\text { of TL7 (mm) }\end{array}$ \\
\hline $3 / 40$ & $3 / 22$ & $3 / 7$ & $3 / 13.7$ & $3 / 11.8$ & $3 / 16.2$ & $3 / 12$ \\
\hline
\end{tabular}

\section{Results}

\subsection{Single frequency rectifier}

The output of rectifier is described using parameters such as reflection coefficient, output voltage, RF to DC conversion efficiency, and value impedance at operating frequency. The reflection coefficient is a parameter that describes how much of a wave is reflected by discontinuities presents in transmission medium. A reflection coefficient is a ratio of the reflected wave and the incident wave. The efficiency of RF to DC conversion is defined as the ratio of
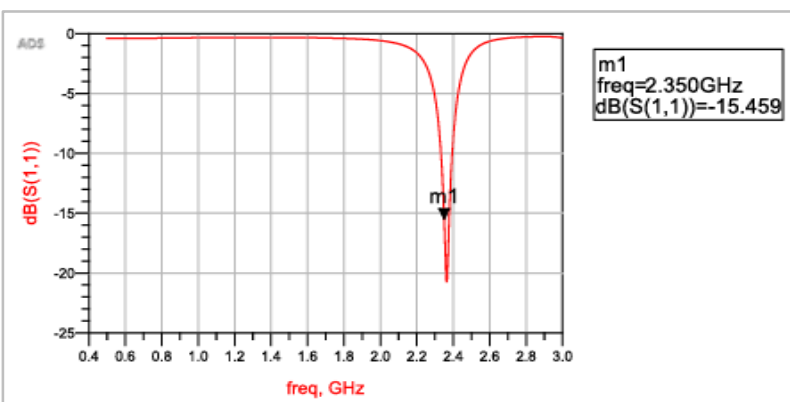

output DC power (Pout) to input RF power (Pin). Figures 6 and 7 depict the plots of the reflection coefficient and output voltage for the $2.35 \mathrm{GHz}$ and $2.42 \mathrm{GHz}$ rectifiers, respectively. As shown in Figures 6 and 7, both rectifiers have S11 values that are greater than the standard value of $-10 \mathrm{~dB}$ at respective frequencies and the output voltage of obtained for $0 \mathrm{dBm}$ input power for both the rectifiers is sufficient to energize a low power device.

Figure 6 Plot of reflection coefficient and output voltage for $2.35 \mathrm{GHz}$ rectifier
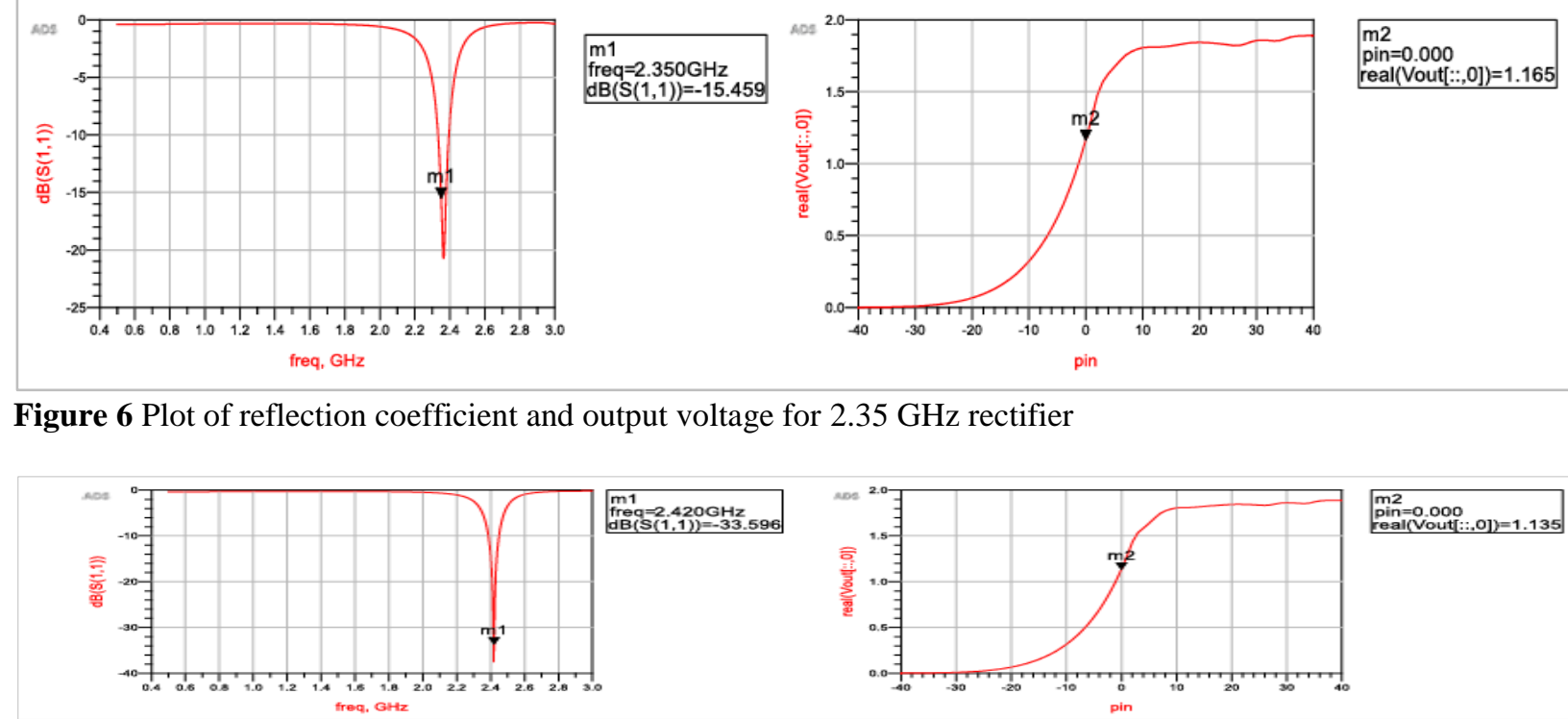

Figure 7 Plot of reflection coefficient and output voltage for $2.42 \mathrm{GHz}$ rectifier

Figures 8 and 9 show the efficiency and impedance plots for both rectifiers. Both rectifiers have conversion efficiencies greater than $40 \%$ at $0 \mathrm{dBm}$ input power and impedance values close to $50 \Omega$ at their respective frequencies. It is also observed that as input power increases, so does output voltage, but efficiency decreases, so the impedance and output voltage values are adjusted for maximum efficiency. The reason for the lower efficiency and output voltage for both of above design is that energy is 
harvested from only one frequency; the efficiency can be increased further by harvesting energy from multiple frequencies simultaneously, as described in the following section.

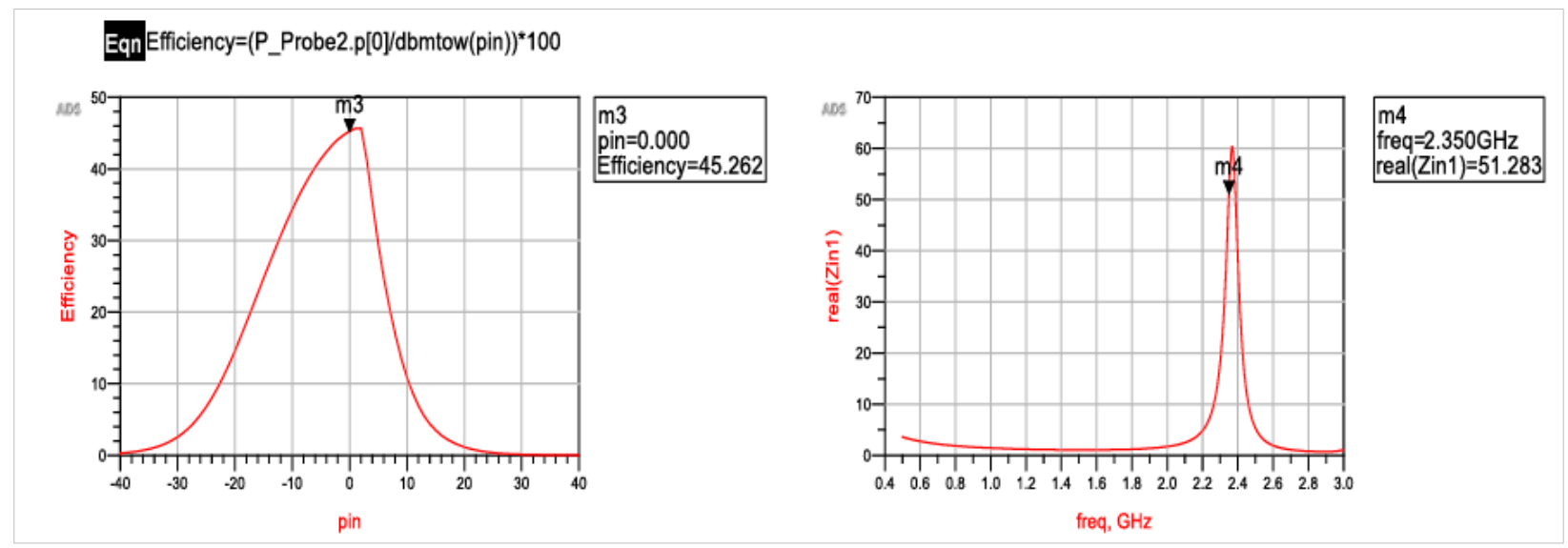

Figure 8 Plot of efficiency and impedance for $2.35 \mathrm{GHz}$ rectifier

Eqn $=$ fficiency $=($ P_Probe2.p[0]/dbmtow(pin) $) * 100$

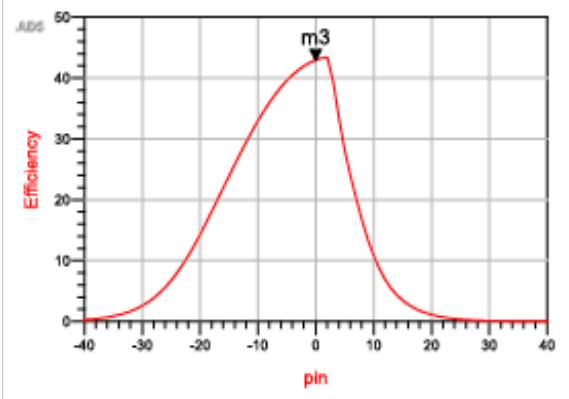

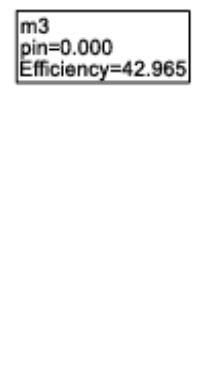

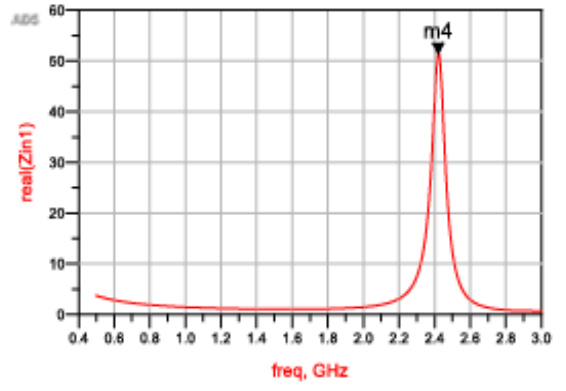

Figure 9 Plot of efficiency and impedance for $2.42 \mathrm{GHz}$ rectifier

\subsection{Dual band rectifier}

Figure 8 shows that the maximum efficiency is 44.8 $\%$ at $2.35 \mathrm{GHz}$ frequency; to improve efficiency further, a dual-band rectifier is required. This section discusses the performance of two different rectifiers that cover the LTE, ISM, and Global System for Mobile Communications (GSM) bands. Figure 10 shows simulated results for dual band rectifier working at $1.8 \mathrm{GHz}(\mathrm{GSM})$ and $2.41 \mathrm{GHz}$ (Wi-Fi) frequencies. As illustrated in Figure 10, the rectifier operates at $1.840 \mathrm{GHz}$ GSM (marker $\mathrm{m} 1$ ), and 2.42 $\mathrm{GHz}$ (Wi-Fi) (marker m2), frequencies. When energy is harvested from both frequencies simultaneously, the output voltage is $1.61 \mathrm{~V}$ (marker m3) and the conversion efficiency is $52.37 \%$ (marker $\mathrm{m} 4$ ) at 0 $\mathrm{dBm}$ input power. At $-4 \mathrm{dBm} \mathrm{i} / \mathrm{p}$ power, the efficiency increases to $79.46 \%$ (marker m9). Figure 10 also shows that the rectifier's impedance is nearly equal to $50 \Omega$ at both frequencies. The rectifier's impedance is matched, and the load resistance value is tuned for maximum efficiency; as a result, the efficiency and output voltage are increased for above rectifier. 


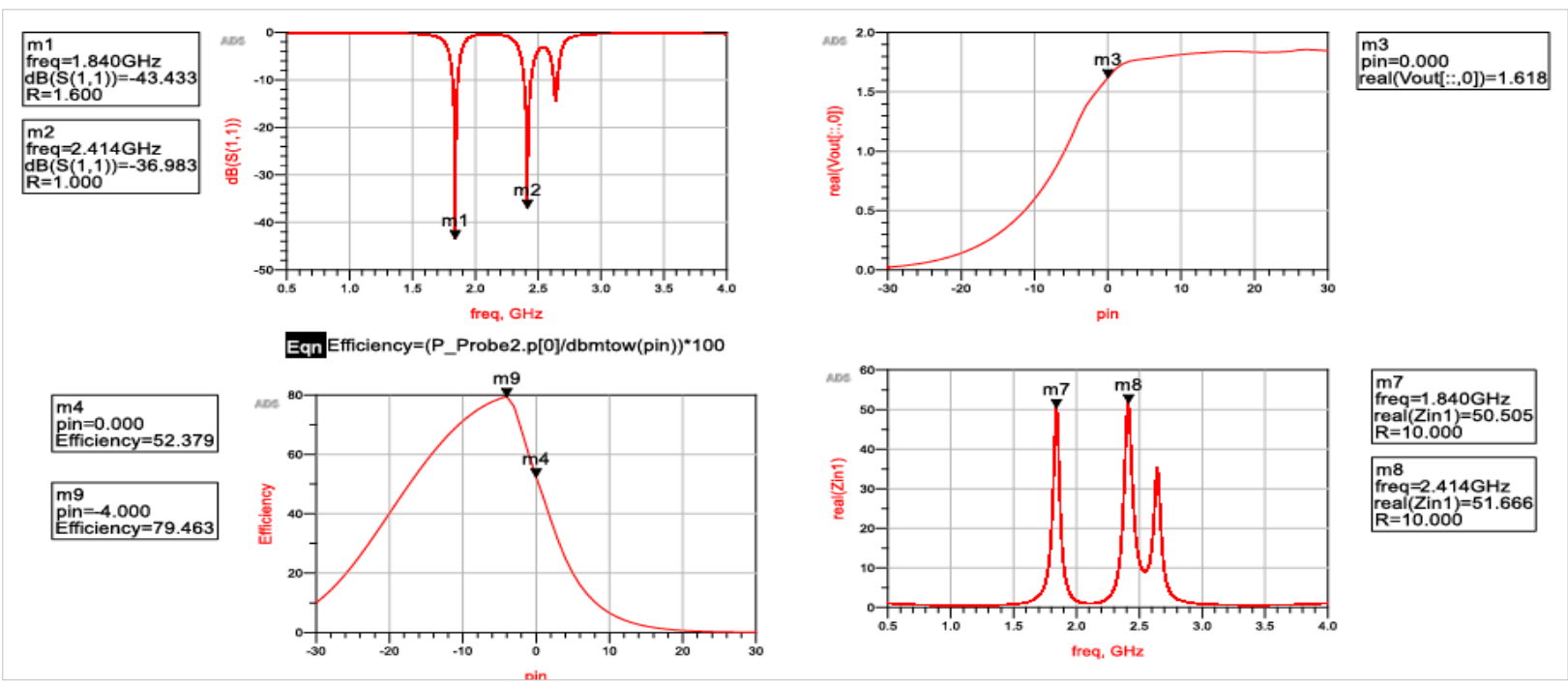

Figure 10 Simulated results for reflection coefficient, output voltage \& RF to DC conversion efficiency for dual band rectifier

Figure 11 represents the simulated results for another rectifier designed for LTE $(883 \mathrm{MHz} \& 2.35 \mathrm{GHz})$ bands. As shown in Figure 11, the reflection coefficient is greater than $-10 \mathrm{~dB}$ at both frequencies, and the RF to DC conversion efficiency is increased to $86.32 \%$ at $-4 \mathrm{dBm}$ input power for this rectifier. When the input power is $30 \mathrm{dBm}$, the output voltage rises to $1.86 \mathrm{~V}$ (marker $\mathrm{m} 4$ ), while when it is $0 \mathrm{dBm}$, it falls to $1.67 \mathrm{~V}$ (marker $\mathrm{m} 3$ ), the reason for this is that more signal power requires more energy to be harvested. The impedance value (marker $\mathrm{m} 8$ and $\mathrm{m} 9$ ) is nearly equal to the standard value of $50 \Omega$ and shows perfect matching at both frequencies.

Finally a comparison of the simulated results of both dual-band rectifiers is presented in Table 5. As described below, the efficiency of the second rectifier designed for LTE bands is greater than that of the first, but the output voltage is nearly identical in both cases. We can increase the output voltage even further by adding a Power Management Unit (PMU) after rectifier.

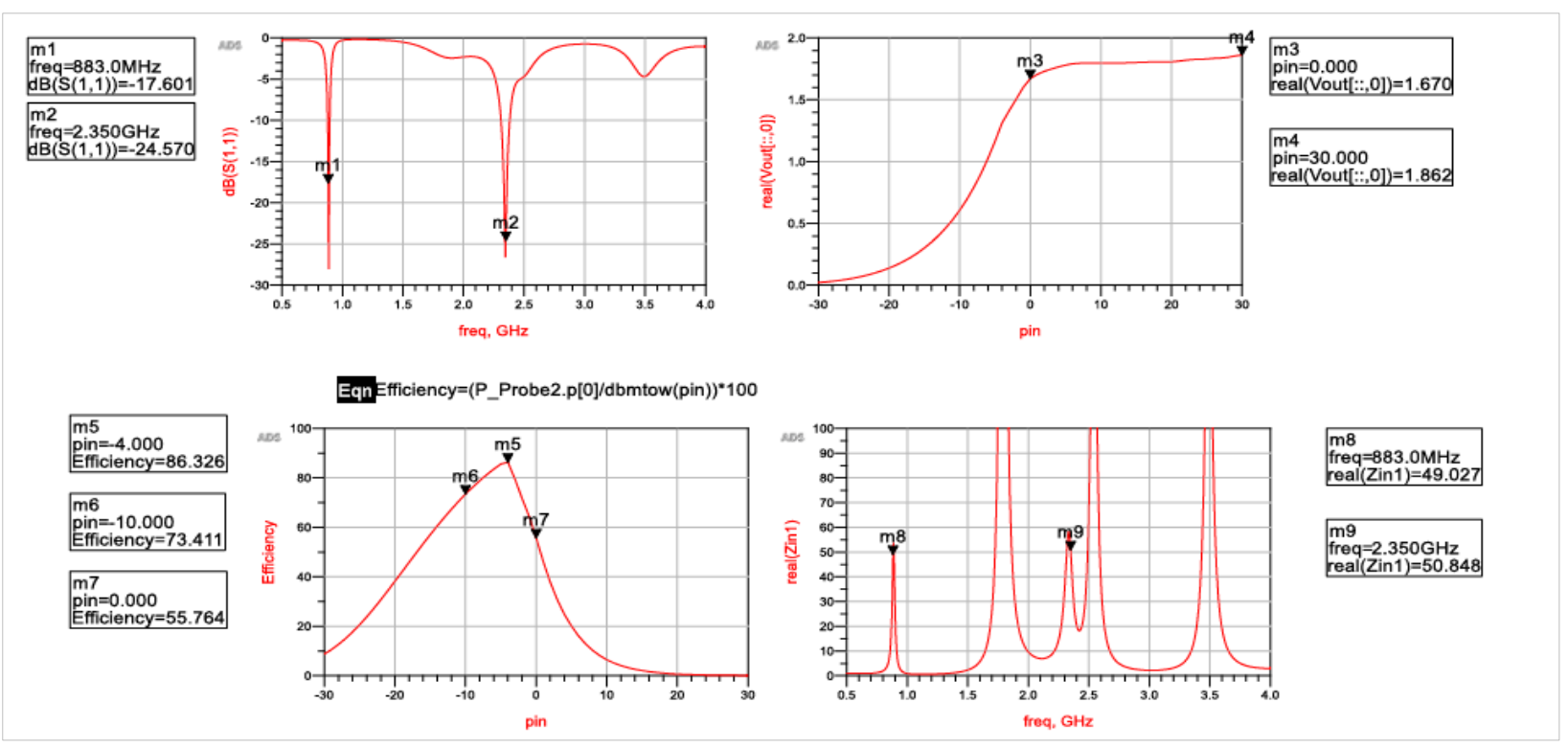

Figure 11 Simulated results for rectifier operating at LTE bands 
Table 5 Comparison of simulated results of dual-band rectifier

\begin{tabular}{|c|c|c|c|}
\hline $\begin{array}{l}\text { Operating frequency } \\
(\mathbf{G H z})\end{array}$ & $\begin{array}{l}\text { Output voltage } \\
\text { Vout (V) }\end{array}$ & $\begin{array}{l}\text { RF-DC conversion efficiency } \\
(\%) @-4 \mathrm{dBm} \text { i/p power }\end{array}$ & Input impedance (Zin) ( $(\mathbf{)})$ \\
\hline $1.84 \& 2.42 \mathrm{GHz}$ & 1.61 & 79.46 & $\begin{array}{l}50.50 \Omega @ 1.84 \mathrm{GHz} \\
51.66 \Omega @ 2.42 \mathrm{GHz}\end{array}$ \\
\hline $883 \mathrm{MHz} \& 2.35 \mathrm{GHz}$ & 1.67 & 86.32 & $\begin{array}{l}49.02 \Omega @ 883 \mathrm{MHz} \\
50.84 \Omega @ 2.35 \mathrm{GHz}\end{array}$ \\
\hline
\end{tabular}

\section{Discussion}

It is observed from results that the conversion efficiency of rectifier is increased with dual band operation and proposed design achieve higher efficiency suitable for low power applications. It is seen that sufficient output voltage is harvested using designed rectifiers and used for powering low power devices. The simulated results show that there is no impedance mismatch at the respective frequencies, resulting in higher efficiency.

\subsection{Comparison with related work}

A comparison of the proposed rectifier with related work is presented in Table 6. In [10] a dual-band rectifier is proposed, but the simulated efficiency is $60 \%$ at $0 \mathrm{dBm}$. In $[11,12,13]$ a dual-band rectifier is designed with a lower dialectic constant substrate material to achieve more efficiency, and the input power for maximum efficiency is greater. In $[19,20]$ a multiband rectifier is proposed but efficiency is reduced. Table 6 also shows that the proposed design achieves more efficiency using simple design \& lowcost substrate with the simultaneous dual-frequency operation.

\subsection{Limitations}

The proposed rectifier operates at a single frequency and in dual bands, has a narrow impedance bandwidth, and is not compact, which is preferred in low power devices. The transmission lines used in the circuit can be modeled as an L section or an inverted $\mathrm{U}$ section for a compact design of the rectifier.

Table 6 Comparison of proposed work with related work

\begin{tabular}{|c|c|c|c|c|c|c|c|c|}
\hline $\begin{array}{l}\text { Ref. } \\
\text { no. }\end{array}$ & $\begin{array}{l}\text { Operating } \\
\text { frequency } \\
(\mathrm{MHz})\end{array}$ & $\begin{array}{c}\text { Substrate } \\
\text { used }\end{array}$ & Diode used & $\begin{array}{l}\text { Rectifier } \\
\text { topology }\end{array}$ & $\begin{array}{c}\text { Load } \\
\text { resistance } \\
\text { @ output } \\
(\mathrm{K} \Omega)\end{array}$ & $\begin{array}{c}\text { Simulated } \\
\eta_{(\text {RF-DC })}(\%)\end{array}$ & $\begin{array}{c}\text { Input } \\
\text { power for } \\
\text { maximum } \\
\text { efficiency \& } \\
\text { output } \\
\text { voltage } \\
\text { (dBm) } \\
\end{array}$ & $\begin{array}{l}\text { Simulated } \\
\text { output } \\
\text { DC } \\
\text { voltage } \\
\text { (V) }\end{array}$ \\
\hline [10] & $925 \& 2450$ & FR4 & SMS7630 & $\begin{array}{l}\text { Voltage } \\
\text { doubler }\end{array}$ & 4 & $\begin{array}{l}60 @ 925 \& \\
2450 \mathrm{MHz} .\end{array}$ & 0 & 1.43 \\
\hline [11] & $\begin{array}{c}1850 \& \\
2450\end{array}$ & $\begin{array}{c}\text { RT/Duroid } \\
5880\end{array}$ & HSMS285C & $\begin{array}{l}\text { full wave } \\
\text { Greinacher }\end{array}$ & 6.7 & $\begin{array}{l}70 @ 1800 \\
\mathrm{MHz} \& \\
2450 \mathrm{MHz}\end{array}$ & 9 & 6.1 \\
\hline [12] & $\begin{array}{c}1700 \& \\
2400\end{array}$ & $\begin{array}{l}\text { Taconic } \\
\text { TLY-5 }\end{array}$ & HSMS2828 & $\begin{array}{l}\text { Bridge } \\
\text { diode }\end{array}$ & $669 \Omega$ & $\begin{array}{l}86 @ 1.7 \\
\mathrm{GHz} \& 75 \\
@ 2.4 \mathrm{GHz}\end{array}$ & 27 & 3 \\
\hline [13] & $\begin{array}{c}1950 \& \\
2500\end{array}$ & RO3003 & HSMS2850 & $\begin{array}{l}\text { Voltage } \\
\text { doubler }\end{array}$ & 1.1 & $\begin{array}{l}63 @ 1950 \\
\mathrm{MHz} \\
69 @ 2500\end{array}$ & 7 & $3 . .5$ \\
\hline [19] & $\begin{array}{c}900,1800, \\
2600\end{array}$ & Paper & HSMS2850 & $\begin{array}{c}\text { Rectifier } \\
\text { with } 4 \\
\text { diodes }\end{array}$ & 6.3 & $35,23,15$ & -15 & 1.3 \\
\hline [20] & $\begin{array}{c}1800,2100 \\
2300\end{array}$ & $\begin{array}{l}\text { Roger's } \\
\text { 4003C }\end{array}$ & SMS7630 & $\begin{array}{l}\text { Voltage } \\
\text { doubler }\end{array}$ & 3.3 & $44,35,42$ & 0 & 1.3 \\
\hline $\begin{array}{l}\text { Proposed } \\
\text { Work }\end{array}$ & $\begin{array}{c}1840 \& \\
2420 \\
883 \& \\
2350\end{array}$ & FR4 & SMS7630 & $\begin{array}{l}\text { Voltage } \\
\text { doubler }\end{array}$ & 5 & $\begin{array}{l}79.46 \\
\text { overall \& } \\
86.32 \\
\text { overall }\end{array}$ & -4 & 1.5 \\
\hline
\end{tabular}




\section{Conclusion and future work}

In this paper, two single frequency $(2.35 \mathrm{GHz}$ and $2.42 \mathrm{GHz})$ and two dual-band $(1.84 \mathrm{GHz} \& 2.42 \mathrm{GHz}$ and $883 \mathrm{MHz} \& 2.35 \mathrm{GHz}$ ) rectifiers are designed using SMS7630 diode. The rectifiers are built with a low-cost FR4 substrate and have optimal load resistance values of $3 \mathrm{~K} \Omega$ and $5 \mathrm{~K} \Omega$ respectively. At $-4 \mathrm{dBm}$ input power, the overall efficiency of the rectifier is $79.46 \%$ and $86.32 \%$, respectively, while the maximum output voltage obtained is $1.67 \mathrm{~V}$ at 0 $\mathrm{dBm}$ input power. The overall efficiency of the rectifier is greater than $50 \%$ for input power ranging from $-10 \mathrm{dBm}$ to $0 \mathrm{dBm}$, allowing it to be used for real-world low power applications. Future work involves reducing the size of rectifier and combining a dual-band rectifier with an antenna to form a rectenna.

A complete list of abbreviations is shown in Appendix I.

\section{Acknowledgment}

The authors would like to thank the editor and reviewers whose comments and suggestions helped in improving the quality of the manuscript.

\section{Conflicts of interest}

The authors have no conflicts of interest to declare.

\section{References}

[1] Jose J, George S, Bosco L, Bhandari J, Fernandes F, Kotrashetti A. A review of RF energy harvesting systems in India. In international conference on technologies for sustainable development 2015 (pp. 14). IEEE.

[2] Tran LG, Cha HK, Park WT. RF power harvesting: a review on designing methodologies and applications. Micro and Nano Systems Letters. 2017; 5(1):1-16.

[3] Trikolikar A, Lahudkar S. A review on design of compact rectenna for RF energy harvesting. In international conference on electronics and sustainable communication systems 2020 (pp. 651-4). IEEE.

[4] Muhammad S, Jiat TJ, Kin WS, Iqbal A, Alibakhshikenari M, Limiti E. Compact rectifier circuit design for harvesting GSM/900 ambient energy. Electronics. 2020; 9(10):1-11.

[5] Xiao YY, Ou JH, Du ZX, Zhang XY, Che W, Xue Q. Compact microwave rectifier with wide input power dynamic range based on integrated impedance compression network. IEEE Access. 2019; 7:15187887.

[6] Kasar Ö, Gözel MA, Kahriman M. Analysis of rectifier stage number and load resistance in an RF energy harvesting circuit. Microwave and Optical Technology Letters. 2020; 62(4):1542-7.

[7] Ismail N, Abd KE. Reversed L-type matching impedance of RF-to-DC rectifier for energy harvesting system. Journal of Electrical and Electronic Systems Research. 2021; 19:167-72.

[8] Pinto D, Arun A, Lenka S, Colaco L, Khanolkar S, Betgeri S, et al. Design and performance evaluation of a Wi-Fi energy harvester for energizing low power devices. In region 10 symposium 2021 (pp. 1-8). IEEE.

[9] Narayanan S and Thangavel S. A compact two sleeve microstrip patch rectenna system for ambient RF energy harvesting. International Journal of Engineering Research \& Technology. 2021; 10(6):716-23.

[10] Vu NAH, Thien NM, Trinh LH, Nguyen VT, Ferrero F. Compact dual-band rectenna based on dual-mode metal-rimmed antenna. Electronics. 2020; 9(9):1-12.

[11] Chandravanshi S, Akhtar MJ. An efficient dual-band rectenna using symmetrical rectifying circuit and slotted monopole antenna array. International Journal of RF and Microwave Computer-Aided Engineering. 2020; 30(4).

[12] Rotenberg SA, Podilchak SK, Re PD, Mateo-segura C, Goussetis G, Lee J. Efficient rectifier for wireless power transmission systems. IEEE Transactions on Microwave Theory and Techniques. 2020; 68(5):1921-32.

[13] Aboualalaa M, Mansour I, Mansour M, Bedair A, Allam A, Abo-zahhad M, et al. Dual-band rectenna using voltage doubler rectifier and four-section matching network. In wireless power transfer conference 2018 (pp. 1-4). IEEE.

[14] Papadopoulou MS, Boursianis AD, Goudos SK, Psannis K. Dual-band rectifier design for ambient RF energy harvesting. In world symposium on communication engineering 2020 (pp. 7-11). IEEE.

[15] Muhammad S, Tiang JJ, Wong SK, Smida A, Ghayoula R, Iqbal A. A dual-band ambient energy harvesting rectenna design for wireless power communications. IEEE Access. 2021; 9:99944-53.

[16] Coskuner E, Garcia-Garcia JJ. Metamaterial impedance matching network for ambient RF-energy harvesting operating at $2.4 \mathrm{GHz}$ and $5 \mathrm{GHz}$. Electronics. 2021; 10(10):1-14.

[17] Yusoff SS, Malik SA, Ibrahim T. Simulation and performance analysis of a dual GSM band rectifier circuit for ambient RF energy harvesting. Applications of Modelling and Simulation. 2021; 5:125-33.

[18] Li S, Cheng F, Gu C, Yu S, Huang K. Efficient dualband rectifier using stepped impedance stub matching network for wireless energy harvesting. IEEE Microwave and Wireless Components Letters. 2021;31(7):921-4.

[19] Palazzi V, Hester J, Bito J, Alimenti F, Kalialakis C, Collado A, et al. A novel ultra-lightweight multiband rectenna on paper for RF energy harvesting in the next generation LTE bands. IEEE Transactions on Microwave Theory and Techniques. 2017; 66(1):36679.

[20] Polaiah G, Krishnamoorthy K, Kulkarni M. Compact high-efficiency pentahedron and quatrefoil shape antennas with enhanced gain for GSM1800, 3G, 4G- 
LTE energy harvesting applications. International Journal of Microwave and Wireless Technologies. 2021; 13(3):274-85.

[21] Ahmad W, Qureshi MI, Khan WT. A highly efficient tri band (GSM1800, WiFi2400 and WiFi5000) rectifier for various radio frequency harvesting applications. In progress in electromagnetics research symposium-fall 2017 (pp. 2039-44). IEEE.

[22] Tafekirt H, Pelegri-sebastia J, Bouajaj A, Reda BM. A sensitive triple-band rectifier for energy harvesting applications. IEEE Access. 2020; 8:73659-64.

[23] Tung N. Multi-band ambient RF energy harvesting rectifier for autonomous wireless sensor networks. In region 10 conference 2016 (pp. 3736-9). IEEE.

[24] Boursianis AD, Papadopoulou MS, Koulouridis S, Rocca P, Georgiadis A, Tentzeris MM, et al. Tripleband single-layer rectenna for outdoor RF energy harvesting applications. Sensors. 2021; 21(10):1-18.

[25] Wang SH, Zheng SY, Leung KW, Xia MH. A selfmatched multi-band rectifier for efficient electromagnetic energy harvesting. IEEE Transactions on Circuits and Systems I: Regular Papers. 2021; 68(11):4556-65.

[26] Skaik T. A quad-band rectifier design with improved matching bandwidth for RF energy harvesting applications. In international conference on promising electronic technologies 2017 (pp. 82-6). IEEE.

[27] Hsu CY, Lin SC, Tsai ZM. Quadband rectifier using resonant matching networks for enhanced harvesting capability. IEEE Microwave and Wireless Components Letters. 2017; 27(7):669-71.

[28] Selim KK, Wu S, Saleeb DA, Ghoneim SS. A quadband RF circuit for enhancement of energy harvesting. Electronics. 2021; 10(10):1-28.

[29] He Z, Liu C. A compact high-efficiency broadband rectifier with a wide dynamic range of input power for energy harvesting. IEEE Microwave and Wireless Components Letters. 2020; 30(4):433-6.

[30] https://www.keysight.com/in/en/lib/resources/software -releases/ads-2016.html. Accessed 30 September 2021.

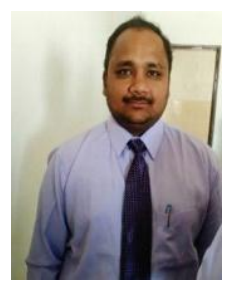

Mr. Anand Trikolikar received the M.Tech. degree in Electronics and Telecommunication Engineering from Dr. Babasaheb Ambedkar Technological University, Lonere, Maharashtra, India in 2011. He is currently pursuing $\mathrm{PhD}$ degree from AISSMS Institute of Information Technology, Pune, India. $\mathrm{He}$ is working as Assistant Professor in the Department of E\&TC, Imperial College of Engineering \& Research, Wagholi, Pune, India. His research interests are Energy Harvesting, Antenna Design and Communication Engineering.

Email:anandt15@gmail.com

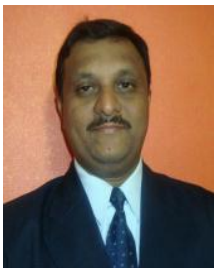

Dr. Swapnil Lahudkar obtained his $\mathrm{PhD}$ degree in 2012 from Bharati Vidyapeeth University, College of Engineering. He is currently working as Professor in the Department of Electronics \& Telecommunication at JSPM's Imperial College of Engineering, Pune. He is the author of more than 40 papers in peer reviewed journals. His area of interest includes Communication, Antenna Designing and Signal Processing.

Email: swapnillahudkar@gmail.com

Appendix I

\begin{tabular}{lll}
\hline S. No. & Abbreviation & Description \\
\hline 1 & AC & Alternating Current \\
2 & ADS & Advanced Design System \\
3 & DC & Direct Current \\
4 & FR4 & Flame Retardant 4 \\
5 & GHz & Giga Hertz \\
6 & GSM & Global System for Mobile \\
& & Communication \\
7 & IMN & Impedance Matching Network \\
8 & IoT & Internet of Things \\
9 & ISM & Industrial, Scientific, and Medical \\
10 & LTE & Long Term Evaluation \\
11 & MHz & Mega Hertz \\
12 & PCE & Power Conversion Efficiency \\
13 & PMU & Power Management Unit \\
14 & RF & Radio Frequency \\
15 & RFEH & Radio Frequency Energy Harvesting \\
16 & Wi-Fi & Wireless Fidelity \\
17 & WSN & Wireless Sensor Network \\
18 & Zin & Input Impedance \\
\hline
\end{tabular}

